\title{
Ant-nest corrosion failure of heat exchangers copper pipes
}

\author{
Luca Cozzarini a *, Lucia Marsich a, Chiara Schmid ${ }^{\text {a }}$ \\ a Department of Engineering and Architecture, University of Trieste, Via Valerio 6A, I-34127 \\ Trieste, Italy. \\ *corresponding author. Luca Cozzarini -: Icozzarini@units.it
}

\begin{abstract}
This paper reports on the failure analysis carried out on leaking copper pipes from three different air conditioning systems. Pinhole leaks originating from localized corrosion morphology were reported. Microscopic interconnecting tunnels inside the pipe section were observed; these tunnels were filled with corrosion products. Experimental findings and similarity to previously reported cases pointed out a corrosion mechanism known as "antnest corrosion" as failure cause. This type of corrosion could develop in heat exchanger components stored after assembly, during leakage tests or in the initial operational stages. It was shown that an ant-nest corrosion attack could start due to different reasons and propagate in different ways (from the inside or from the outside of the tube). In the first examined case, it was supposed that the hydrolysis of a halocarbon gas circulating in the pipe was the triggering cause of the corrosion event; in the other cases, we ascribed the starting corrosion event to the presence of residual organic contaminants on the external pipe surface.
\end{abstract}

\section{Keywords}

ant-nest corrosion; copper pipes; heat exchanger; optical microscopy; scanning electron microscopy. 


\section{Introduction}

Copper, thanks to its high thermal conductivity, is commonly used in heat-transfer applications, such as radiators, condensers, refrigerators and air conditioning [1-3]. This paper reports on the failure analysis of three different copper tubes used in heat exchangers due to a peculiar type of corrosion attack known as "ant-nest" or "formicary" corrosion, which is particularly difficult to diagnose and prevent. Leakages and premature failures of thinwalled copper tubing in heat exchanger have been frequently reported as a direct result of this corrosion [2-8]. It has been speculated that this form of corrosion, firstly described in the late ' 70 s [5], causes approximately $10 \%$ of copper heat exchanger failures worldwide $[7,8]$. The corrosion pattern is characterized by microscopic tunnels (not noticeable by naked eye observation) that propagate randomly inside the tube wall, forming interconnecting longitudinal networks similar to an ant nest when observed in cross section $[6,9,10]$. Corrosion rate of this process is quite fast $\left(10 \mathrm{~mm} /\right.$ day at $0.3 \mathrm{~mA} \mathrm{~cm}^{-2}$ [11]). Given enough time (usually weeks or months) these tunnels will migrate completely through the tube wall and cause leaking $[7,11]$. Corrosion products filling the tunnels, mainly copper (I) oxide, may be transported on the tube surface [7]. It is commonly recognized that ant-nest corrosion of copper tubes is triggered by the simultaneous presence of air, moisture and carboxylic acids [7-11]. Some authors show that short-chain carboxylic acids can be originated from residual organic compounds (such as synthetic lubricant oils, degreasing or anti-tarnishing agents) [12-14], anthropogenic or biogenic processes [11], or even by decomposition of paints or hemicellose in the wood or hydrolysis of halocarbon refrigerants [13]. Briefly, in the commonly accepted corrosion mechanism, carboxylic acids attack the patina covering the copper surface, composed by an outer layer of cupric oxide/hydroxide, to form unstable cuprous carboxylate complexes and cuprous oxide. The volume expansion caused by the deposited cuprous oxide causes formation of micro cracks that expose more copper surface to the corrosive environment. In this study, we report on the failure analysis carried out on leaking copper pipes from three different air conditioning systems. Experimental observations pointed out typical ant-nest corrosion features. We show that this corrosion path can was propagate in different direction (from the inside or from the outside of the tube) and originate from different triggering causes.

\section{Material and methods}

In all cases, sections from failed tubes were sawn off for analysis; areas next to leakage points were cut and prepared for metallographic examination. Metallographic sections were prepared by enclosing samples in epoxy resin and polishing their surface with successive steps (down to $1 \mu \mathrm{m}$ diamond paste). Stereo Microscopy (SM) images were acquired by an Optika SZN-2 stereo microscope; Optical Microscopy (OM) images were collected by a Nikon Optiphot-REFBD; Scanning Electron Microscopy (SEM) investigation was performed by a Leica Stereoscan 430i equipped with a Pentafet Plus TM detector for Energy Dispersive Spectrometry (EDS) analysis. X-Ray Diffraction (XRD) patterns were recorded on a Bruker D5005 diffractometer operating at $40 \mathrm{kV} / 20 \mathrm{~mA}$ using Cu Ka $(E=8.04 \mathrm{keV} ; \lambda=1.5406 \AA)$, over a $10^{\circ}<2 \theta<70^{\circ}$ angular range (angular resolution: $0.05^{\circ}$; time/step: $4 \mathrm{~s}$ ). 


\section{Results}

\subsection{Failure analysis - Case 1}

This case examined copper U-tubes from an air conditioning heat exchanger. No failure was noticed during manufacturer's pressure test. After test, pipes were drained and stored in air before commissioning. No specific drying procedure after water drainage was reported. Tubes have an outer diameter of $9.5 \mathrm{~mm}$ ( $3 / 8$ inches) and a wall thickness of $0.25 \mathrm{~mm}$; leaking happened next to the U-tube bends (area highlighted in Figure 1). The conveyed fluid was a halocarbon gas; the leakage happened after 2 month of service.

Outer surfaces of the straight regions of the tubes show a typical roughness originating from wire drawing production process. Any obvious defects have not been observed. Inner surfaces of U-tubes are instead characterized by dark spots, already noticeable by visual examination (Figure 2 ) and clearly visible by SM (Figure 3 ). These spots are larger and more concentrated in the upper part of the U-tube (Figure 4 - magnification of "B" zone of Figure 2). Dark spots and surrounding areas have been further investigated by SEM (Figure 5).

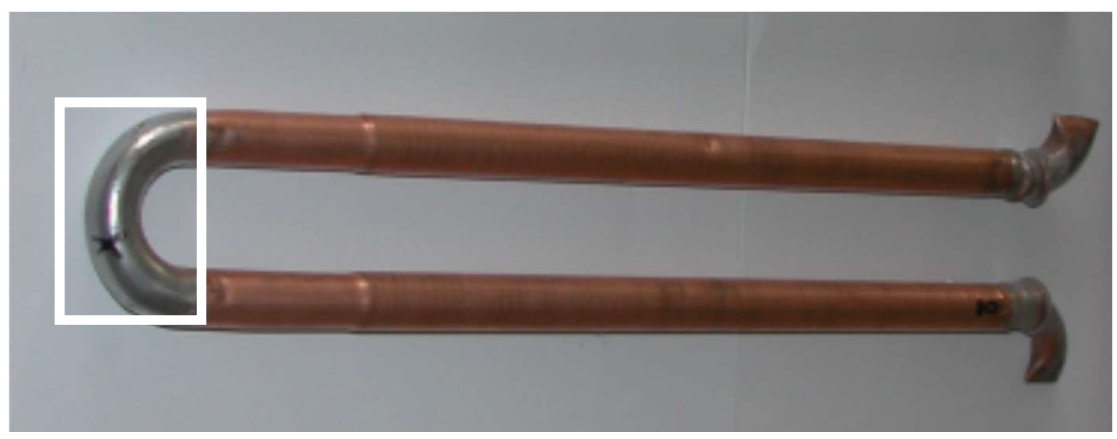

Figure 1: failed tube from Case 1 - leakage area is highlighted in the white rectangle.

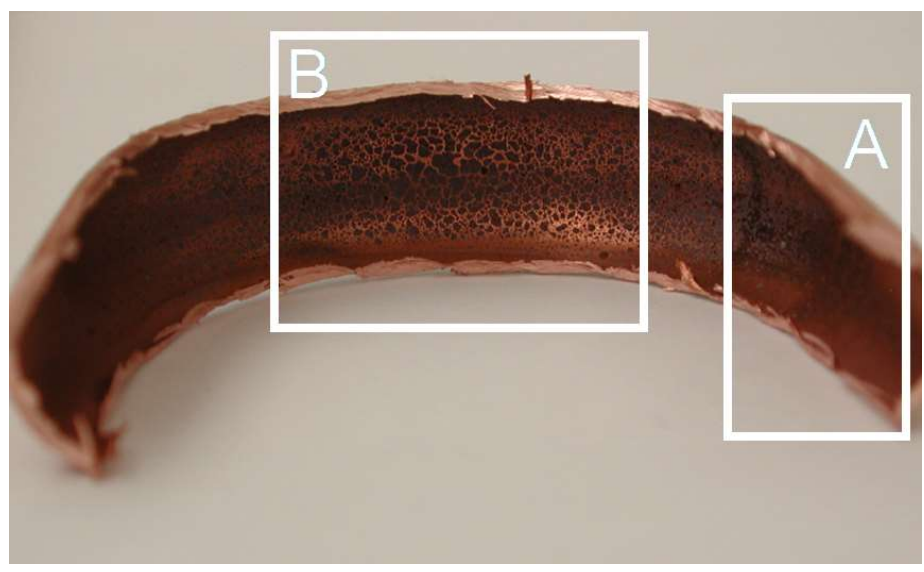

Figure 2: visual examination of inner surface of U-tubes from Case 1. Magnification of zone " $A$ " and zone "B" are shown in Figure 3 and Figure 4. 


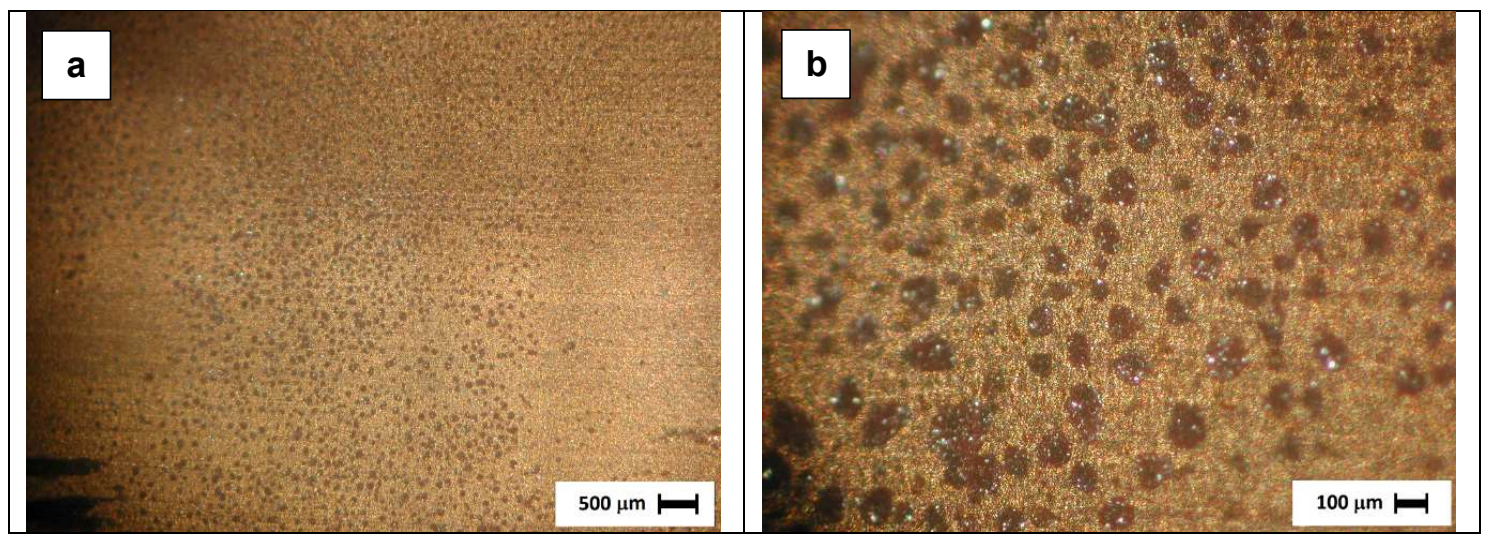

Figure 3: area "A" from Figure 2 (inner surface of U-tubes) magnified by stereo microscope. (a) lower magnification; (b) higher magnification.

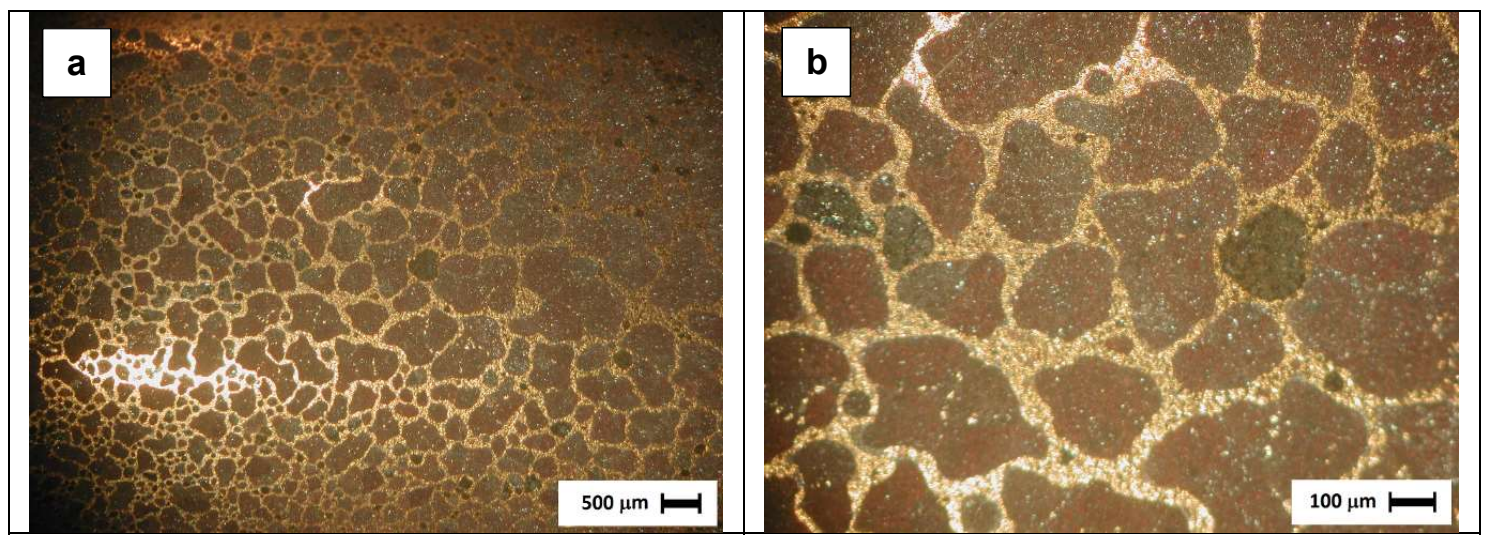

Figure 4: area "B" from Figure 2 (inner surface of U-tubes) magnified by stereo microscope. (a) lower magnification; (b) higher magnification.

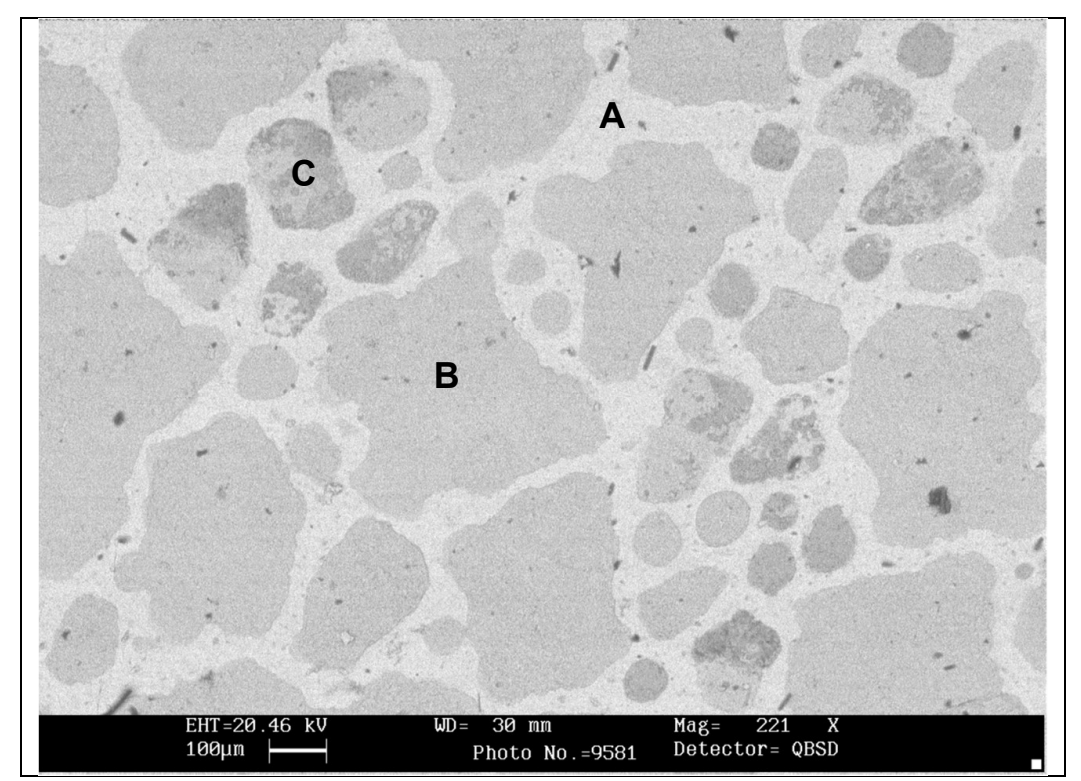

Figure 5: dark spots on inner surface of U-tubes from Case 1 examined at SEM. (A): bright area; (B): light grey area; (C) dark grey area. 


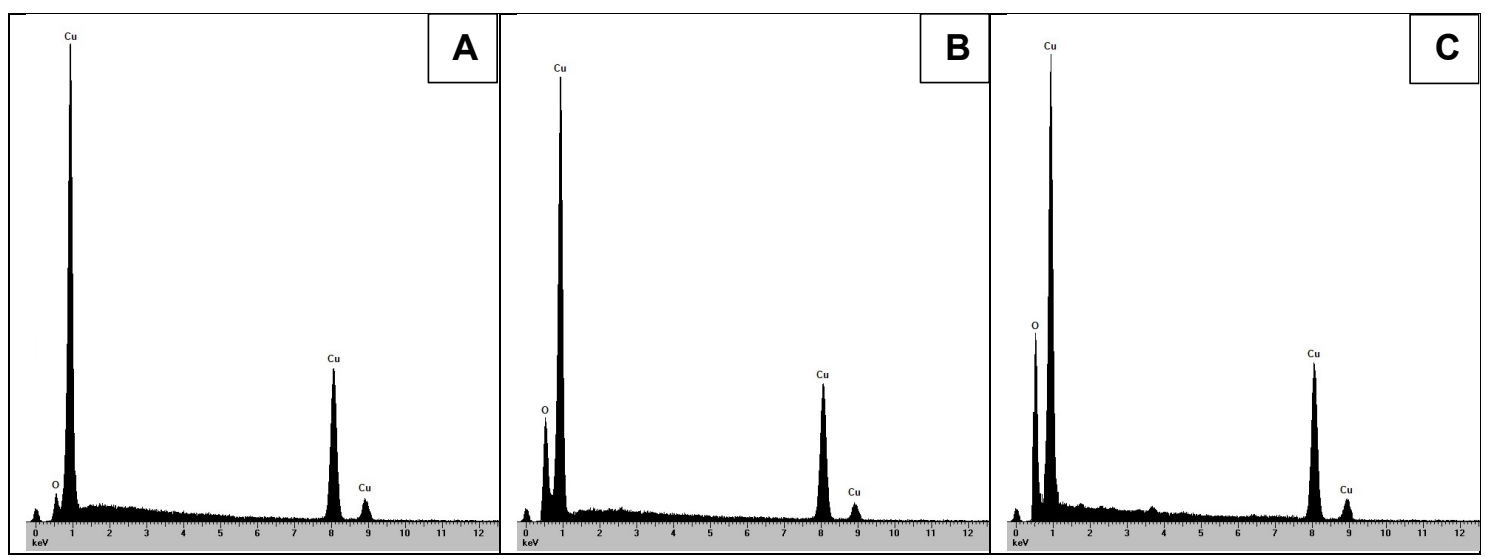

Figure 6: EDS of inner surface of U-tubes from Case 1: (A): bright area; (B): light grey area; (C) dark grey area.

SEM images (Figure 5 - backscattered electrons contrast: higher atomic number appears brighter) show dark areas surrounded by a brighter matrix. Comparing these images with $\mathrm{SM}$, and taking into account different colors of $\mathrm{Cu}$-based compounds and atomic numbers of $\mathrm{Cu}$ and $\mathrm{O}$, we can speculate the composition of the different areas. Bright areas ("A" in Figure 5) are identifiable as $\mathrm{Cu}$ (higher atomic number; bright and reflective in optical images), light grey areas ("B" in Figure 5) as $\mathrm{Cu}_{2} \mathrm{O}$ (dark red in optical images) and dark grey areas (" $\mathrm{C}$ " in Figure 5) as $\mathrm{CuO}$ (black in optical images; this compound is the one having the lowest average atomic number). EDS on these areas (Figure 6) pointed out a higher $\mathrm{O} / \mathrm{Cu}$ ratio in " $\mathrm{C}$ " respect to " $\mathrm{B}$ ", fitting with the compounds assignments.

Optical images (Figure 7 and Figure 8 ) of metallographic sections show pit damage starting from the inner towards the outer surface of the tube. Smaller pits appear also on the outer surface. Some damaged areas emerge in the middle of the pipe wall. Higher magnification images show bright red precipitated inside the pits.

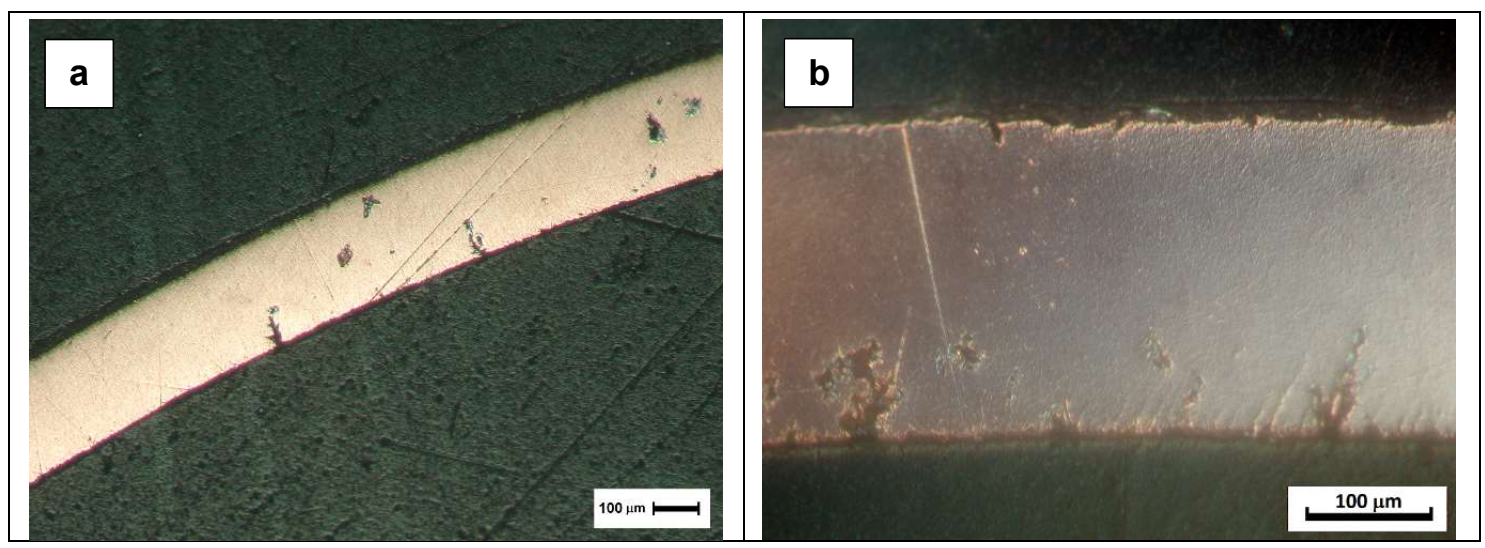

Figure 7: failed tubes from Case 1 - metallographic section observed at stereo optical microscope. (a) lower magnification; (b) higher magnification. 


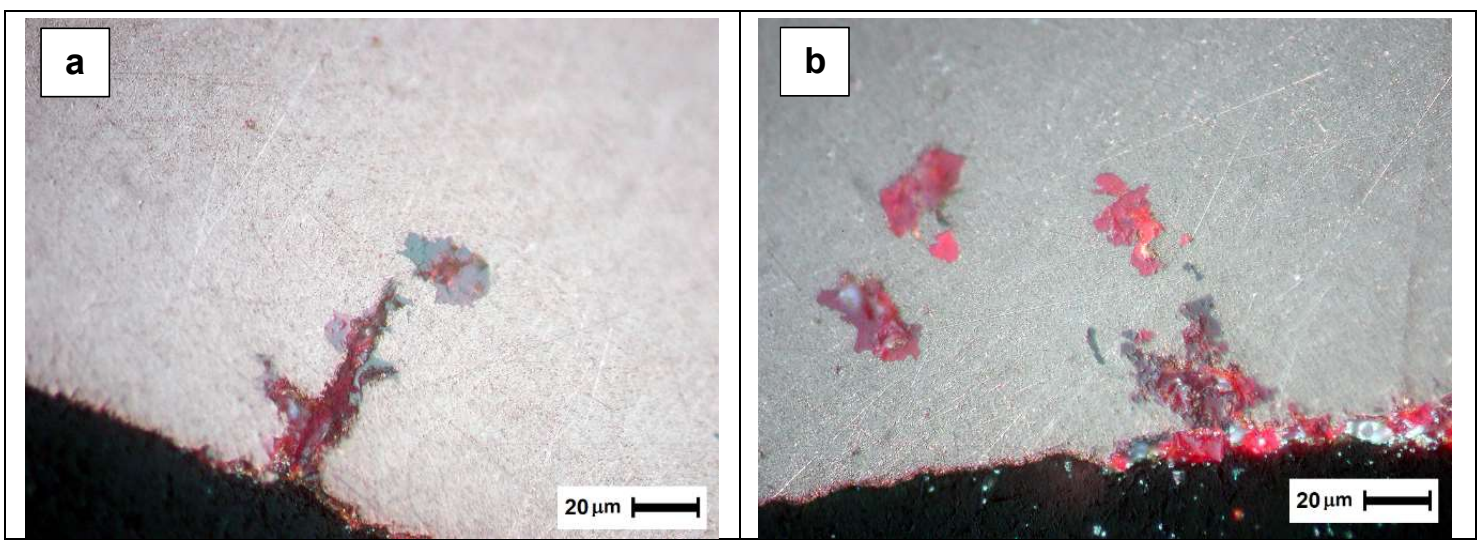

Figure 8: failed tubes from Case 1 - metallographic section observed at optical microscope (higher magnification details of tunnels); (a) shows a pit growing from internal towards external surface; (b) shows some pits passing longitudinally through the wall

\subsection{Failure analysis - Case 2}

This case reports on a failed shell-and-tube heat exchanger from an office air conditioning system. Tubes are internally grooved; they have an outer diameter of $8 \mathrm{~mm}$ and a wall thickness of $0.28 \mathrm{~mm}$; the outer surface is smooth; the tube material is copper. The conveyed fluid was a R-134 (1,1,1,2-tetrafluoroethane); the external fluid was water. The heat exchanger leaked after 1 years of operations. After manufacturing, pressure test was performed with water and no leakage was detected. After test, pipes were drained, sealed and then stored for 5 months before commissioning. A specific drying procedure before sealing and storing was not planned. A black crust can be observed on the outer surfaces of the tubes (Figure 9a); this crust has been identified by XRD as mixture of $\mathrm{CuO}$ and $\mathrm{Cu}_{2} \mathrm{O}$ (Figure 10). Some areas of the crust were detached, revealing red spots (Figure 11a). After SEM/EDS observation, these areas were identified as pits with inner deposits of $\mathrm{Cu}_{2} \mathrm{O}$, due to the higher $\mathrm{O} / \mathrm{Cu}$ ratio respect to the dark spots (Figure 12). Pipe section show pits growing from external wall towards the inside (optical microscope: Figure 13a; SEM: Figure 13b,c).

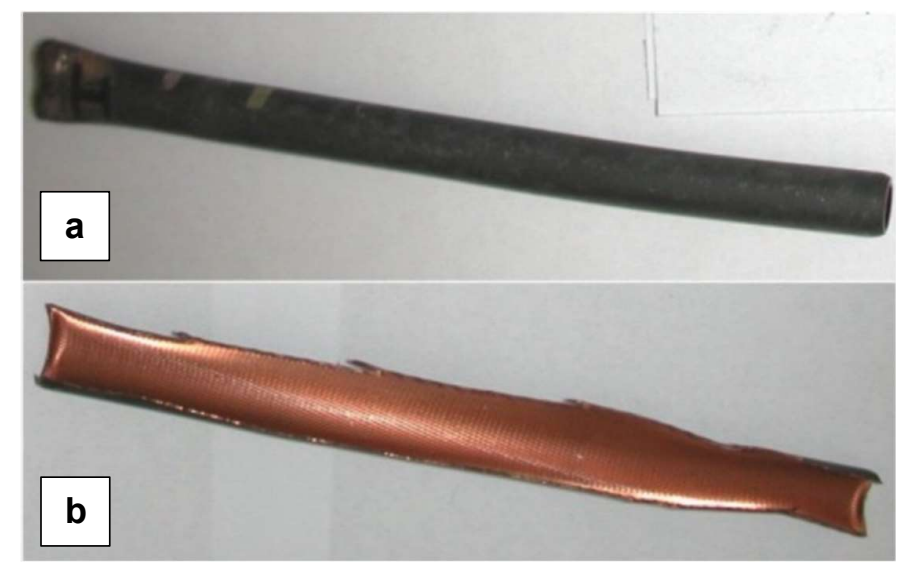

Figure 9: failed tube from Case 2 - (a) external surface; (b) internal surface. 


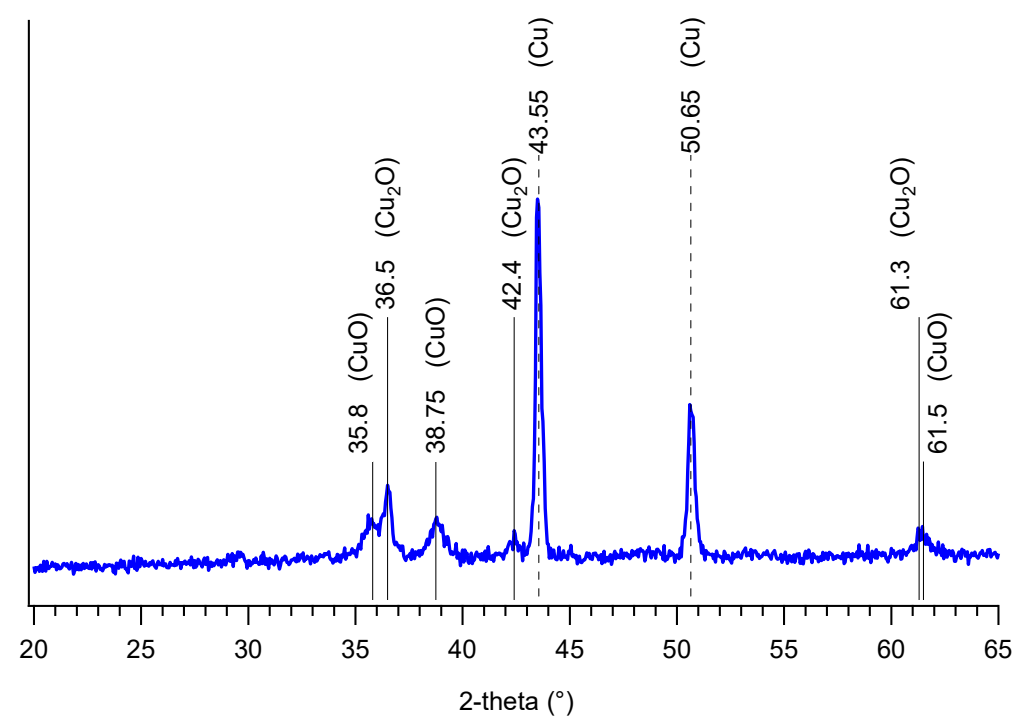

Figure 10: XRD on external surface of failed tube from Case 2

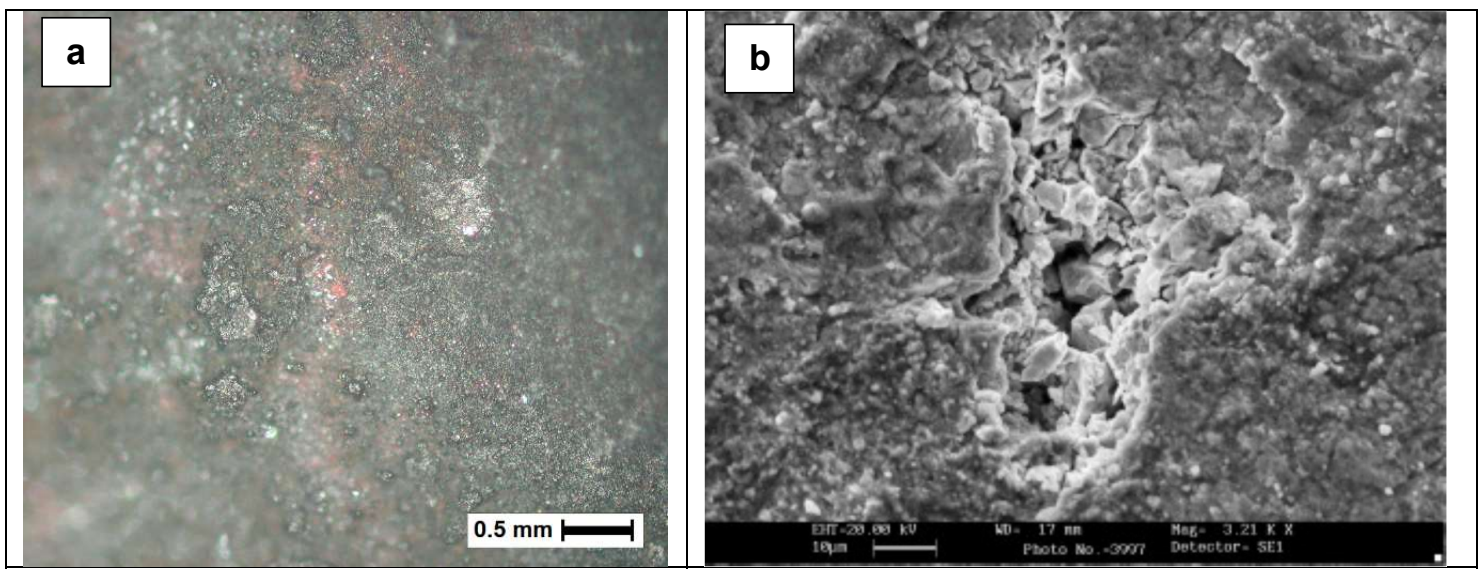

Figure 11: failed tubes from Case 2 - external surface; (a) examined at optical microscope and (b) SEM detail of the pit.

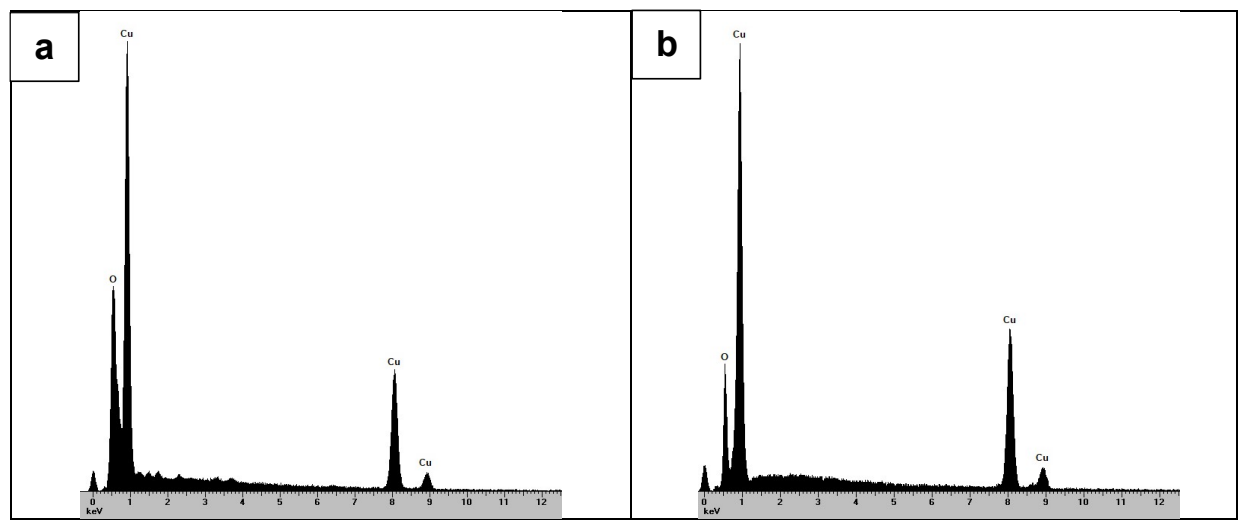

Figure 12: EDS of failed tubes from Case 2: (a) red deposit inside the pit; (b) dark external crust 


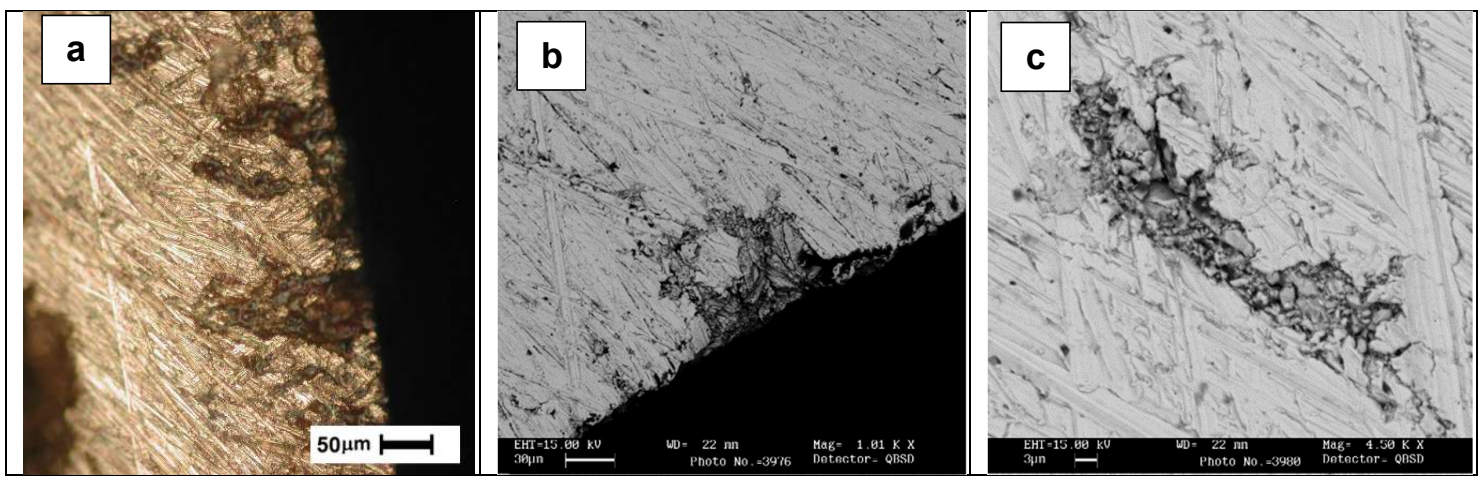

Figure 13: failed tubes from Case 2 - metallographic section showing pit growing from external towards internal surface; (a) examined at optical microscope and (b,c) SEM. (b) shows a pit passing longitudinally through the wall.

\subsection{Failure analysis - Case 3}

This case is similar to Case 2, but pipes derived from a different heat exchanger installed in a shopping mall in another location (pipes are shown in Figure 14). Tube material, geometry and components history are the same as those reported for Case 2. After trial tests, pipes were drained, sealed and then stored for 2 years. No specific drying procedure was applied. Leaking failure happened just after commissioning.

Greenish crusts, black and red deposits were observed on outer surface (Figure 15). Metallographic inspection points out pits growing through the wall section, from outside towards inside (Figure 16). Several elements ( $\mathrm{Si}, \mathrm{S}, \mathrm{Cl}, \mathrm{K}, \mathrm{Ca}, \mathrm{Fe}$ ) in addition to $\mathrm{Cu}$ and $\mathrm{O}$ were detected by EDS In the external crust (Figure 17). XRD of external crust (Figure 18) reveals the presence of $\mathrm{CuO}, \mathrm{Cu}_{2} \mathrm{O}$ and basic copper carbonate. Corrosion morphologies similar to those already seen in Case 2 were observed on the internal wall.

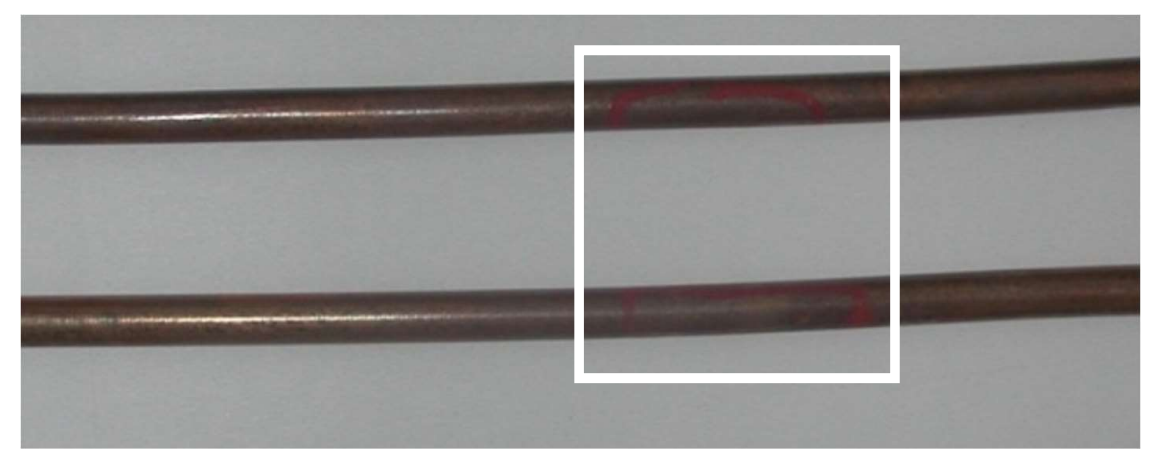

Figure 14: failed tubes from Case 3 - leakage area is highlighted in the white rectangle. 


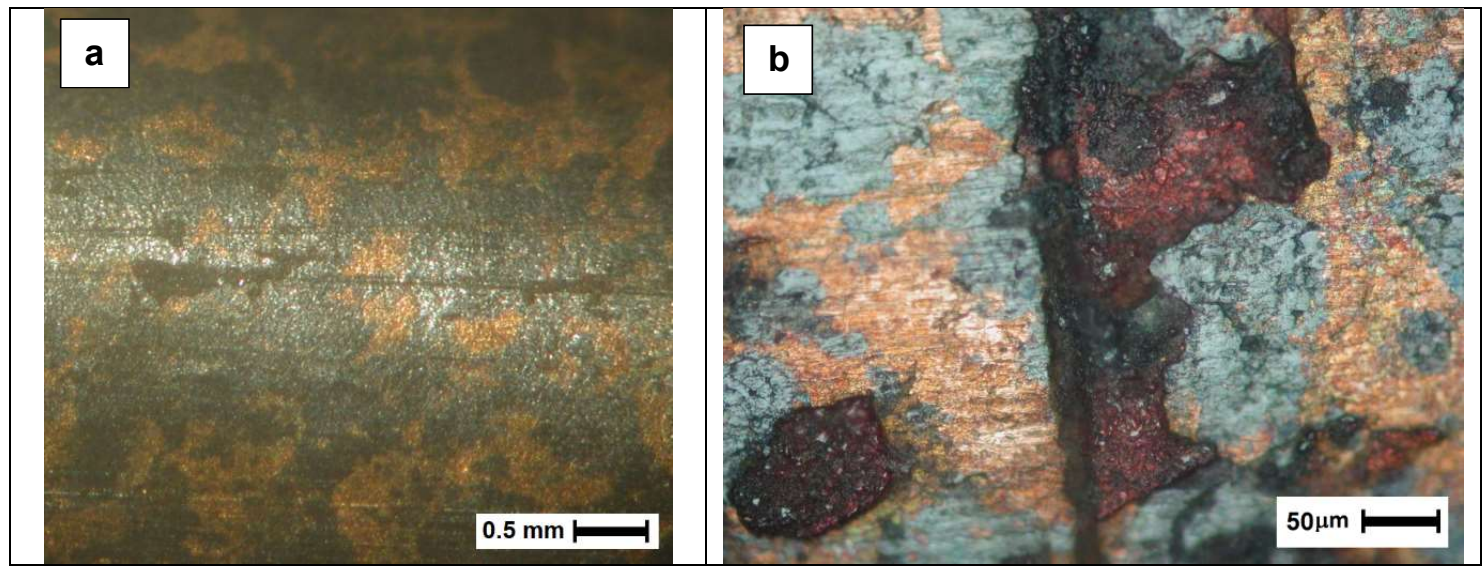

Figure 15: failed tubes from Case 3 - external surface; (a) examined at stereo microscope and (b) optical microscope.

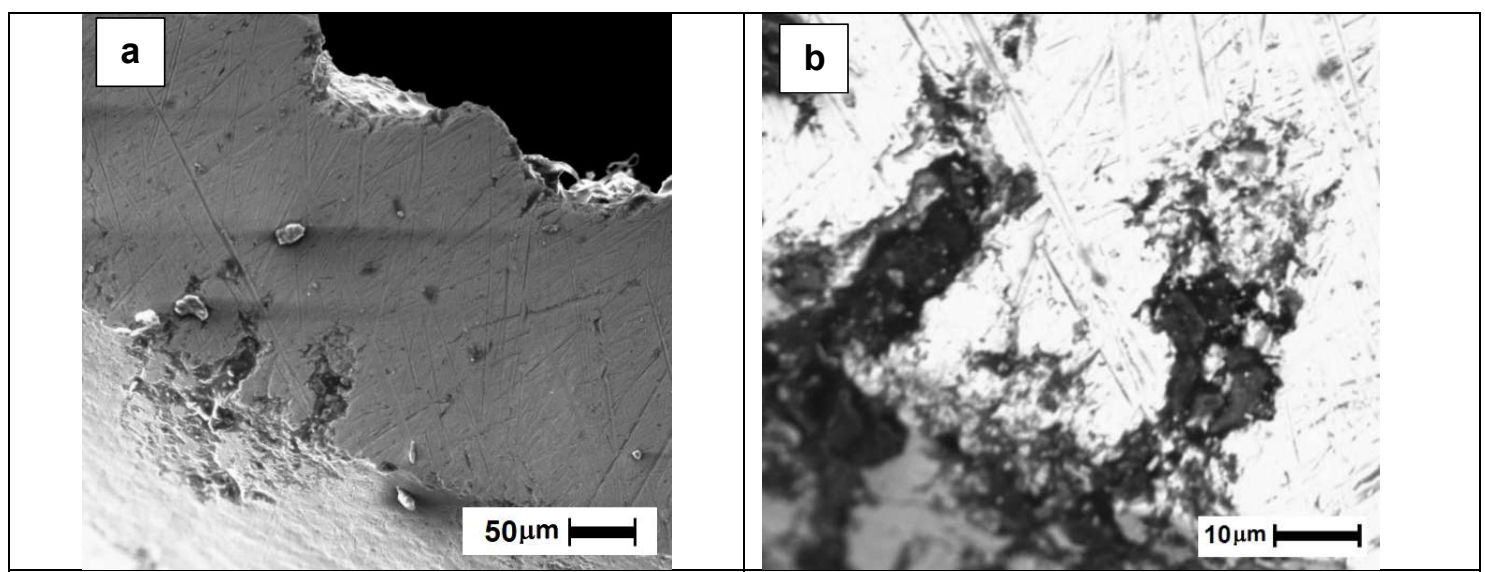

Figure 16: failed tubes from Case 3 - metallographic section showing pit growing from external towards internal surface, examined at SEM. (a) lower magnification; (b) higher magnification

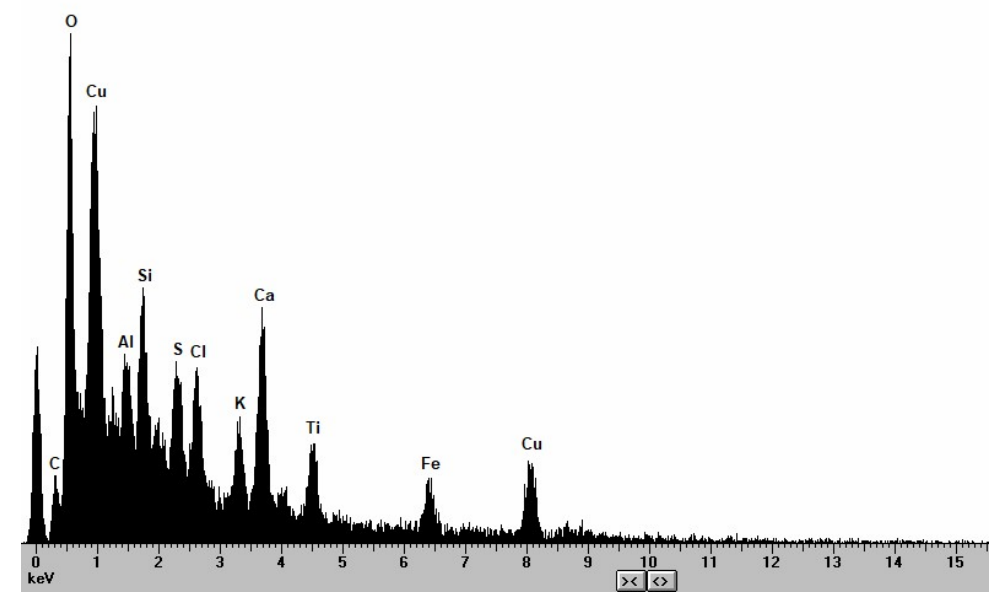

Figure 17: EDS on deposits of failed tube from Case 3 


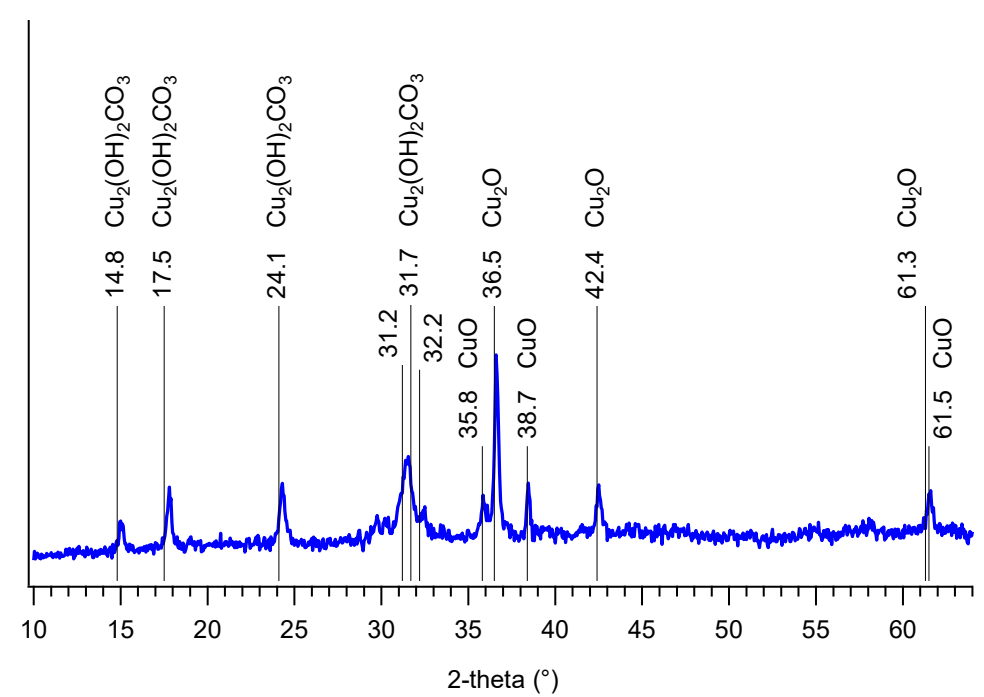

Figure 18: XRD on external surface of failed tube from Case 3

\section{Discussion}

A general accepted mechanism of ant-nest corrosion involves several steps, requiring the simultaneous presence of air, moisture and carboxylic acids [2,6-8,10-14]. In presence of carboxylic acids, such as formic or acetic acid, copper ions can form unstable cuprous carboxylate complexes; these compounds oxidize to form cupric carboxylate and cuprous oxide. The volume expansion caused by the deposited cuprous oxide causes a wedging effect within the pit, resulting in the formation of micro cracks that expose more copper surface to the corrosive environment, giving more cuprous carboxylate. Once started, antnest corrosion is a self-sustaining process; reactions described above repeat until tunnels propagate through the walls leading to a leaking failure of the pipes.

In the first case, the conveyed fluid was Freon, a halocarbon gas well known to be a triggering agent for ant-nest corrosion $[13,15]$. The hydrolysis of halocarbon refrigerants could lead to the formation of formaldehyde as byproduct. Formaldehyde itself oxidizes in humid atmosphere to formic acid, starting the ant-nest corrosion cycle. Corrosion evolved from inside towards outside of the pipe walls. The damage was concentrated in the U-tube area, which is the most stressed one due to fluid flow and residual mechanical stresses. This support the interpretation reported by other authors $[13,16]$, which speculate a synergic chemical-mechanical activation of the ant-nest corrosion process. Water is indeed necessary to hydrolyze halocarbon residues; water origin is likely from air humidity (pipes were not sealed during storage) or from trial tests residual water (a proper drying procedure was not reported).

Experimental findings reported in Case 2 and Case 3 are similar, even if samples originated from different locations. In these cases, pipes were drained from water and were sealed after trial tests, then stored for long times (months or years). The corrosion attack started from the outer surface, oppositely to the mechanism reported in the first case, where the attack started from the inner surface. External fluid was tap water from water supply system (two different supply systems in the two cases), which is not a sufficient condition to start an antnest corrosion event. In Case 3, presence of chlorides has been hypothesized on the surface deposits; these can be originated from anti-fouling agents or biocides. Another 
possible triggering cause could be the presence of residual organic compounds (such as synthetic lubricant oils or degreasing agents) that can decompose to carboxylic acids in presence of moisture [12-14] .These compounds are generally used in degreasing, cleaning, pickling and joining operations in the tube manufacturing, and can be left on the pipe surface. These leftovers could have been the starting points of the corrosion events.

\section{Conclusions}

A failure analysis was carried out on copper pipes originated from three different heat exchanger systems. Experimental observations show features typical of an ant-nest corrosion mechanism for all the three cases. It was shown that an ant-nest corrosion attack could start due to different reasons and propagate in different ways (from the inside or from the outside of the tube). Since this type of corrosion requires the concurrent presence of air, moisture and carboxylic acids to be initiated, the removal of any of these should avoid this problem. Valid prevention measures that have been suggested $[4,14]$ against ant-nest corrosion include the use of lubricants oils with low-carboxylic acid content, proper drying and sealing of the pipes prior to storage and drastic removal of all possible contaminants.

\section{References}

[1] E. Cano, J. L. Polo, A. López-Caballero, J. M. Bastidas, Copper corrosion in air conditioning systems, Corros. Prev. Control 52 (2005), 56-58.

[2] A. Vazdirvanidis, S. Papadopoulou, S. Papaefthymiou, G. Pantazopoulos, D. Skarmoutsos, Copper tubing failure due to ant-nest corrosion, MATEC Web of Conferences 188 (2018), 03005.

[3] E. Cano J. Simancas, J. L. Polo, C.L. Torres, J. M. Bastidas, J. Alcolea, Early corrosion failure of copper tubing used in air-conditioning units, Materials and Corrosion 50 (1999), 103-110.

[4] T. Notoya, Ant Nest Corrosion in Copper Tubes, Corrosion Engineering 39 (1990), 315-320.

[5] J. O. Edwards, R. I. Hamilton, J. B. Gilmour, Early Corrosion Failures in Copper Heat Exchanger Tubing, Mater. Perform. 16 (1977), 18-20.

[6] H. Peltola, M. Lindgren, Failure analysis of a copper tube in a finned heat exchanger, Engineering Failure Analysis 51 (2015), 83-97.

[7] P. Elliot, R. A. Corbett, Ant Nest Corrosion - Exploring the labyrinth, Proceedings of the CORROSION/99 Research Topical Symposium, Paper no. 99342, NACE International, 1999.

[8] R. A. Corbett, P. Elliot, Ant Nest Corrosion - Digging the tunnel, Proceedings of the CORROSION/2000 Research Topical Symposium, Paper no. 00646, NACE International, 2000.

[9] R. S. Situmorang, H. Kawai, Investigating the Mechanism behind 'Ant Nest' Corrosion on Copper Tube, Materials 11 (2018), 533.

[10] T. Notoya, Localized corrosion in copper tubes and the effect of anti-tarnishing pretreatment, Journal of Material Science Letters 10 (1991), 389-391. 
[11] D. M. Bastidas, I Cayuela, J. M. Bastidas., Ant-nest corrosion of copper tubing in airconditioning units, Rev. Metal. Madrid, 42 (2006), 367-381.

[12] H. Baba, T. Kodama, Localized Corrosion of Copper in Wet Organic Acid Vapor, Zairyo-to-Kankyo, 44 (1995) 233-239.

[13] K. Chandra, V. Kain, P.S. Shetty, R. Kishan, Failure analysis of copper tube used in a refrigerating plant, Engineering Failure Analysis 37 (2014), 1-11.

[14] D. M. Bastidas, V. M. La Iglesia, E. Cano, S. Fajardo, J. M. Bastidas, Kinetic Study of Formate Compounds Developed on Copper in the Presence of Formic Acid Vapor, Journal of The Electrochemical Society, 155 (2008), C578-C582.

[15] G. L. Stepakoff, A. P. Modica, The hydrolysis of halocarbon refrigerants in freeze desalination processes. Part I. Solubility and hydrolysis rates of Freon 114 $\left(\mathrm{CCIF}_{2} \mathrm{CCIF}_{2}\right)$, Desalination 12 (1973) 85-105.

[16] J. Zhou, L. Yan, J. Tang, Z. Sun, L. Ma, Interactive effect of ant nest corrosion and stress corrosion on the failure of copper tubes, Engineering Failure Analysis 83 (2018), 9-16.

[17] B. Kuznicka, Erosion-corrosion of heat exchanger tubes, Engineering Failure Analysis 16 (2009) 2382-2387.

Funding sources: this research did not receive any specific grant from funding agencies in the public, commercial or not-for-profit sectors. 